\title{
GUEST EDITOR'S NOTE:
}

\author{
BREAKING BARRIERS IN
}

ORGANIZATIONS FOR THE

PURPOSE OF INCLUSIVENESS

\section{LYNN PERRY WOOTEN}

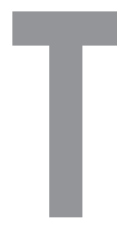

he subjects of workforce diversity and inclusiveness emerged as important topics for human resource managers after the release of influential publications, such as the U.S. Department of Labor's A Report on the Glass Ceiling Initiative (1991) and the Towers Perrin/Hudson Institute's Workforce 2000 book (1987). The Glass Ceiling report defined, validated, and provided a metaphor for the notion that women and minorities confront artificial barriers based on attitudinal or organizational bias that prevent them from advancing upward into management-level positions. Workforce 2000 was an impetus for organizational leaders to acknowledge the aging of the workforce and the entrance of more women, minorities, and immigrants to the workforce.

Both of these seminal reports called for action and the creation of inclusive work environments. For instance, Joyce Miller, executive director of the Glass Ceiling Commission, after the release of the Glass Ceiling report contended corporate leaders and policymakers had to be agents of change and develop solutions: "We know the sob stories. Now we want constructive suggestions" (Salween, 1994). Others, after reading and analyzing the Hudson Institute book, encouraged organizations to embrace diversity as a strategy for vitality, profitability, and competitive advantage (Cox \& Blake, 1991; Hubbard, 2003).

To address the glass ceiling issues and changing workforce demographics, human resource management research and practice began to conceptualize diversity management as an umbrella term for valuing and utilizing the collective talents and contributions of all individuals regardless of differences or similarities in a way that adds a measurable difference to organizational performance (Miller \& Katz, 2002). Furthermore, organizations began to implement an inclusive workplace model for managing diversity that encompasses a broader set of strategies for removing barriers that prevent employees from reaching their highest potential and using their full range of skills and competencies (Harvey, 1999; Robertson, 2006). The implementation of diversity management policies and the creation of inclusive workplaces resulted in programs to address issues, such as cultural awareness, the glass ceiling, sexual harassment, and accommodations for disabled workers.

Correspondence to: Lynn Perry Wooten, Stephen M. Ross School of Business, University of Michigan, Office Location: E4613, 701 Tappan St., Ann Arbor, MI 48109-1234, Phone: 734-763-0486, Fax: 734-764-2557, E-mail: Ipwooten@umich.edu.

Human Resource Management, Summer 2008, Vol. 47, No. 2, Pp. 191-197 


\section{The Multifaceted Aspects of Diversity Management and Inclusion}

Considerable time has passed since workforce diversity emerged on the radar screen of human resource management practitioners, policymakers, and researchers. We have now come to a point where there is a need for reflection to explore what we have learned about managing workforce diversity and to expand the dialogue on breaking barriers for inclusion in organizations. Thus, what do we know about how human resource management polices and leadership practices facilitate inclusive work environments, and how are these behaviors linked to organizational effectiveness? To explore these questions, for this special issue, we sought a broad array of manuscripts that examined the multifaceted aspect of diversity management represented in the Diversity Wheel of Figure 1. We received a record number of submissions; therefore, there will be two parts to this special issue. The second part will be published in August 2008.

The articles in both parts of this special issue not only address race and gender as a component of diversity management, but also look at how organizations support lesbian and gay employees in the workplace, and why managers overlook and underuti-

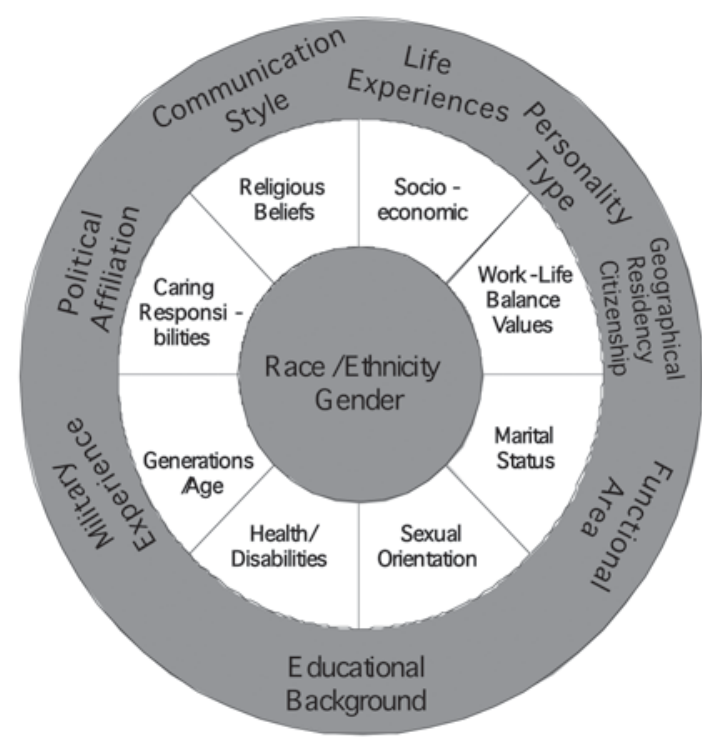

FIGURE 1. The Diversity Wheel lize people with disabilities (e.g., Huffman, Watrous-Rodriguez, \& King; Lengnick-Hall, Gaunt, \& Kulkarni). Contextually, the articles in this special issue employ a variety of settings to study diversity management issues, including traditional corporations, government agencies, universities, and nonprofit organizations. Moreover, the articles in this special issue challenge us to connect different aspects of diversity as an approach for identifying and breaking barriers in organizations. For example, the Altman and Shortland article reviews international work assignments as a mechanism for studying how women overcome prejudices, break institutional barriers, and offer distinct competencies that enhance corporate performance and maximize their potential in the workplace. Similarly, the Murrell, Blake-Beard, Porter, and Perkins-Williamson article analyzes the effects of formal interorganizational and intergenerational mentoring as an alternative to traditional development programs. Thus, their research highlights the significance of working across organizational boundaries and bringing together different generations for helping diverse populations shatter the glass ceiling.

\section{Work-Life Balance Initiatives as a Component of Inclusive Organizational Cultures}

Another theme in this special issue is the importance of work-life balance initiatives for creating inclusive organizational culture. There are few boundaries between our work life and family or personal life (Wooten, 2004). We can attribute this trend to technological advancements, such as personal computers, pagers, fax machines, cell phones, and personal digital assistants (PDAs) that keep us constantly connected to our work. Also, employees feel obligated to work long hours because of peer pressures, fears of downsizing, and intense competition in the global marketplace. Yet, we are no longer a society where the typical employee is a male with a homemaker wife responsible for child care. Instead, in the United States, approximately $78 \%$ of married workers are dual- 
earner couples, and the majority of these workers have child-care or elder-care responsibilities (Bond, Thompson, Gallinsky, \& Prottas, 2002). For single employees, who now represent $20 \%$ of parents in the workforce, the challenges of balancing work, family, and personal life are exacerbated because many are the sole caregivers for their dependents.

If leaders want to succeed at breaking barriers for inclusion, their organizations will incorporate fluid and flexible work-life balance policies to accommodate employees' professional and personal needs. Through practices, inclusive workplaces create a culture that enables both men and women to better meet the competing demands of work and personal life (Coffey \& Tombari, 2005). In addition, these organizations provide resources, tools, and opportunities that help employees integrate work-life priorities and acknowledge that solutions can vary. Therefore, work-life balance initiatives are not a "one-size-fits-all" approach. The ideal solutions adapt to an individual's situation, employee demographics, managerial styles, and organizational attributes. Thus, for work-life balance initiatives to succeed in creating inclusive organizational culture, employers design processes for implementation that are aligned with the employees' needs and organization's supporting infrastructure.

Exploring work-life initiatives as a component of inclusive work cultures, Ryan and Kossek's article in this issue brings to our attention that although many employers adopt policies to support the integration of work with personal and family life, positive gains are not always realized. They contend that this is because practitioners and researchers overlook how variations in implementing work-life initiatives and employee groups foster a culture of inclusiveness. Their research findings provide us with a model for linking the adoption of work-life policies with perceptions of inclusion and positive outcomes by including policy implementation variables as a mediator to fulfilling individual needs and signaling values. Also, Lirio, Dean, Williams, Hangen, and Kossek (to be published in part two, August 2008) investigate how managers facilitate the effective implementation of alternative work arrangements for part-time workers or reduced-load workers. The results of their study suggest that management's behavior and disposition play an important role in fostering inclusiveness for alternative work arrangements.

Also in the second part of this special issue, Root and Wooten's research expands the discussion of how work-life balance challenges create barriers by studying fathers who are shift workers. Through ethnography, their research reveals how the time pressures of shift work impact the ability of fathers to participate in their children's activities. When formal options for flexibility do not work, these employees used informal approaches, such as adhoc arrangements with supervisors, the assistance of coworkers, and some independent actions that put their job at risk.

The conclusions of these studies contribute to the ongoing belief that when managers and leaders are committed and take responsibility for implementing work-life initiatives, the work environment evolves into win-win situations for all organizational stakeholders. However, in the absence of effective work-life balance practices, employees experience tension or the negative spillover effects of this imbalance. This creates a barrier for fulfilling work or family responsibilities and can have negative consequences for the organization.

\section{Breaking Barriers for Inclusion Demands Organizational Change and Learning}

In addition to thinking about the implications of the different components of diversity, the articles in this issue emphasize the perspective that breaking barriers for inclusiveness in organizations is a change process requiring organizational learning. To create a 
work environment of inclusion, people of multiple backgrounds, mind-sets, and thought processes work effectively together and perform at their highest potential to achieve organizational goals (Pless \& Maak, 2004). This is not a simple task, and most organizations do not begin with inclusion or diversity management as a goal (Cross, 2000). Instead, many organizations resist creating inclusive workplaces until confronted with environmental changes or internal pressures. Organizations are designed to foster stability, steadiness, and predictable conditions. However, change is a constant environmenenvironmental force, and it necessitates a tal force, and it necessitates a contradictory behavior from the contradictory behavior from the status quo that moves the organization from its present state and toward a desired future state that increases its effectiveness. status quo that moves the organization from its present state and toward a desired future state that increases its effectiveness (George \& Jones, 2005; Whetten \& Cameron, 2005). We have learned that when organizations engage in the transformation process, change is the platform for building the bridge to support diversity and inclusiveness (Wooten, 2006). When breaking barriers to manage for inclusion, the transformation process of organizational change first involves raising awareness of what diversity management is and its implications for the organization (Pless \& Maak, 2004). This helps create a common basis for shared understanding and envisioning a road map for clarifying the direction of change. The second phase of the change process is action-oriented. The organization assesses and redefines key business principles so that human resource management systems can support the change behavior and culture.

Several articles in this issue analyze the change process organizations employ to create inclusive diversity cultures. Bilimoria, Joy, and Liang (to be published in part two, August 2008) present a study of how academic institutions transform to break barriers so that women science and engineering professors are represented in the ranks and progress through the career ladder. The authors model the transformation process by identifying actions relating to pipeline initiatives and climate initiatives. The Metz and Kulik article also examines change strategies used for creating a diversity-inclusive culture and focus on the public sector. They contend that the change process for making public organizations more inclusive is somewhat different because these organizations often do not define success on the economic metrics that drive change in the private sector, but must pay attention to their reputation, dysfunctional cultures, and the concerns of the public. To illustrate this point, Metz and Kulik report on a case study of Australia's Victoria Police Force and its success at diversity management by beginning with changing the culture with both explicit and tacit actions that involve employees at all levels and external stakeholders.

Other articles in this special issue address different aspects of the change process for breaking barriers for inclusiveness (e.g., Greer \& Virick; Lengnick-Hall, Gaunt, \& Kulkarni; Wong), and interestingly many highlight organizational change as a learning process. When organizations view inclusiveness as a learning process, members develop a knowledge base by engaging in reflective learning (Wooten \& James, 2004). These organizations work diligently to rethink norms and operating rules and reinvent their approaches for adapting to a diverse workforce. Furthermore, the organizational learning not only manifests in their thought process, but there is an actual behavior change. Their acquired knowledge is a catalyst for a paradigm shift that results in a theory of change for guiding action. Furthermore, the articles in this special issue emphasize adopting an opportunistic view of the organizational learning approach for breaking barriers for inclusion. Learning for purposes of inclusion is conceptualized as a cyclical exchange relationship between the organization and its members. The organizations learn by appreciating and using the diversity of its members to incorporate different perspectives into its strategy for attaining 
goals. The learning becomes the core driver of a continuous change process, and the work environment supports learning by encouraging open dialogues, boundaryless relationships, and contributions across hierarchical levels and functional domains (Dass \& Parker, 1999; Thomas \& Ely, 1996).

\section{Breaking Barriers for Inclusion - A Strategic Human Resource Management Investment}

Finally, the articles in this issue advance our knowledge on the practice of inclusion as a strategic human resource management investment. By thinking strategically about diversity, the authors of the articles in this special issue begin with the premise that employees' behaviors, attitudes, and relationships are the cornerstone of human resource management systems and a critical link to the formulation and implementation of an organization's strategy (Bamberger \& Meshoulam, 2000; Cappelli \& Singh, 1992). This is because the set of employee behaviors, attitudes, and relationships has the potential to generate valuable capabilities that contribute to an organizational effectiveness and competitive advantage. Framing human resource management from this perspective views employees as assets and changes the nature of exchange relationship and psychological contract between the employer and employee. The organization tactically thinks about how its processes and actions throughout the human resource management value chain are aligned and contribute to its strategy. This requires strategizing for traditional human resource management activities, such as recruitment, job design training and development, compensation and benefits, retention policies, and the more intangible aspects of human resource management that include building a culture to support organizational initiatives.

Hence, if organizational effectiveness and competitive advantage are a by-product of human capital and the practices and policies that support them, then creating and leveraging inclusive work environments should be a priority for human resource management executives. This begins with an organization's recruitment practices. In this issue, both the Goldberg and Allen article and the Williamson, Slay, Shapiro, and Shivers-Blackwell article research the role of recruitment in creating inclusive workplaces. Goldberg and Allen use signaling theory to study the impact of diversity statements on Web sites as a recruitment tool. Their results suggest parasocially interactive Web sites are an effective means for increasing the diversity of an applicant pool. Williamson and his colleagues find that inclusive recruitment messages consider both race and individual-level attributes. In addition, effective recruitment practices adopt a meaning-based model of advertising diversity practices by incorporating a business-case justification or an inspirational appeal rooted in moral or legal values.

After employees are recruited, training and development activities enable an organization to further invest in human capital and break barriers for inclusion. However, as Chavez and Weisinger assert, managers continue to search for effective diversity management-training programs. They believe this is because of shortcomings of diversity training approaches and introduce an alternative approach to diversity training. Their approach is an active learning process that engages participants through application, analyzing, and synthesizing knowledge with the goal of developing inclusive organizational cultures. This is accomplished when there is holistic transformation in thinking that provides organizational members with an imperative for learning.

Pichler, Simpson, and Stroh (in the second part of the special issue) explore a different aspect of strategic human resource management by investigating the glass ceiling for women in this profession. Their research results suggest a positive relationship 
between employee involvement and the extent which women are represented in lower-level management positions. However they find that although women are concentrated in lower-level of human resource management positions, they are underrepresented in top management. Thus, an invisible barrier still prevents women from reaching the upper echelons of human resource management and serving as strategic partners in organizational decisions. Whereas Greer and Virick focus on inclusive developmental activities by looking at how race and gender diversity are incorporated into succession planning activities. Similarly, their research presents a strategic human resource management perspective by exploring the value of building a diverse bench for the future.

Presenting a holistic view of inclusion as a strategic human resource management investment, Wong takes us inside NASA's Goddard Space Flight Center and discusses changes in the competitive landscape as an imperative for diversity management. This organization has implemented the equity continuum to move beyond affirmative action to valuing and capitalizing on diversity (Wilson, 1998). To implement the equity continuum at NASA's Goddard Space Flight Center, human resource management actives are aligned and support strategic initiatives. As summarized in Wong's article, their Di- versity Strategic Plan outlines actions, goals, and measurable steps for addressing the importance of being an Employer of Choice by creating an inclusive environment for maximizing potential. Moreover, not only is diversity a strategic plan at NASA's Goddard Space Flight Center, but the organization's actions and systems provide the supporting foundation.

\section{A Defining Time for Breaking Barriers in Organizations for the Purpose of Inclusiveness}

In summary, it is our hope that this special issue generates meaningful dialogues on how individuals, groups, and organizations break barriers for inclusion. As research and practice addressing this issue continue, there is a need to further identify trigger points for shattering the glass ceiling, removing silos, and erasing boundaries in organizations. Working together, researchers, policymakers, and practitioners can contribute to the knowledge base on inclusion in organizations by creating a platform for thought and action. Furthermore, we have opportunities for teachable moments to inform others on how inclusive work environments are complementary to other human resource management activities and strategic initiatives, and by seizing the moment, we are on the path to move the inclusion journey forward.

LYNN PERRY WOOTEN is a clinical assistant professor of strategy, management, and organizations at the University of Michigan Ross School of Business. Prior to joining the faculty at the Ross School of Business, she was an assistant professor at the University of Florida. Professor Wooten's research projects focus on sources of competitive advantages in organizations and how firms strategically adapt to changes in their labor markets. In addition, she studies crisis leadership, positive organizing routines, and the effectiveness of diversity programs in organizations. Her research has been published in academic journals, such as the Academy of Management Journal, American Behavioral Scientist, the Journal of Management Inquiry, and Sex Roles. Also her research has been featured in newspapers, industry trade journals, and radio shows. She consults in the areas of strategic human resource management, organizational development, and workforce diversity with both profit and not-for-profit organizations. 


\section{REFERENCES}

Bamberger, P., \& Meshoulam, I. (2000). Human resource strategy: Formulation, implementation and impact. Thousand Oaks, CA: Sage.

Bond, J., Thompson, C., Gallinsky, E., \& Prottas, D. (2002). Highlights of the National Study of the Changing Workforce: Executive summary. New York: Family and Work Institute.

Cappelli, P., \& Singh, H. (1992). Integrating strategic human resources and strategic management. In D. Lewin, O. S. Mitchell, \& P. Sherer (Eds.), Research frontiers in IR and HR (pp. 165-192). Madison, WI: Industrial Relations Research Association.

Coffey, C., \& Tombari, N. (2005, July-August). The bottom-line for work/life leadership: Linking diversity and organizational culture. The Ivey Business Journal Online. Retrieved March 17, 2008, from http:// www.iveybusinessjournal.com/article.asp?intArticle_ID=571

Cox, T., \& Blake, S. (1991). Managing cultural diversity: Implications for organizational competitiveness. Academy of Management Executive, 5(3), 45-56.

Cross, E. (2000). Managing diversity-The courage to lead. Westport, СT: Quorum Books.

Dass, P., \& Parker, B. (1999). Strategies for managing human resource diversity: From resistance to learning. Academy of Management Executive, $13(2), 68-80$.

George, J., \& Jones, G. (2005). Understanding and managing organizational behavior (4th ed.). Englewood Cliffs, NJ: Pearson Prentice-Hall.

Harvey, B. H. (1999). Technology, diversity and work culture-Key trends in the next millennium. HR Magazine, 44, 58-59.

Hubbard, E. (2003). The diversity scorecard: Evaluating the impact of diversity on organizational performance. Burlington, MA: Butterworth-Heinemann.

Miller, F., \& Katz, J. (2002). The inclusion breakthrough. San Francisco, CA: Berrett-Koehler.

Pless, N., \& Maak, T. (2004). Building an inclusive diversity culture: Principles, processes and practices. Journal of Business Ethics, 54, 129-147.

Robertson, Q. M. (2006). Disentangling the meaning of diversity and inclusion in organizations. Group \& Organization Management, 31(2), 212-236.

Salween, K. (1994, January 18). Wanted serious advice only. Wall Street Journal, p. A1.

Thomas, D. A., \& Ely, R. J. (1996). Making differences matter: A new paradigm for managing diversity. Harvard Business Review, 74(5), 79-98.

Towers Perrin/Hudson Institute. (1987). Workforce 2000: Work and workers for the twenty-first century. Indianapolis, IN: Towers Perrin/Hudson Institute.

United States Department of Labor. (1991). A report on the glass ceiling. Washington, DC: Author.

Whetten, D., \& Cameron, K. (2005). Developing management skills (7th ed.). Reading, MA: Addison Wesley Longman.

Wilson, T. (1998). Diversity at work: The business case for equity. Hoboken, $\mathrm{NJ}$ : Wiley.

Wooten, L. (2004). Creating the family-friendly organization. In S. Chowdhury (Ed.), The next generation business handbook: New strategies from tomorrow's thought leaders (pp. 956-970). New York: Wiley.

Wooten, L. (2006). Charting a change course for effective diversity management. Human Factor, 1(2), 46-53.

Wooten, L., \& James, E. (2004). When firms fail to learn: The perpetuation of discrimination in the workplace. Journal of Management Inquiry, 13(1), 23-33. 